\title{
BIOTECHNOLOGY
}

\section{BIOTECH SHOULD BE BARTERED, NOT HIDDEN FROM WORLD COMPETITORS}

7 wo basic issues continue to plague countries which wish to maximize the industrial impact of high technologies for their economies: the drain of technologies to competing powers and Although some new biotechnological developments will always be kept as government or corporate secrets, a mechanism can and should evolve which reduces fears about technology transfer by assuring a fair value of exchange for new technology and offering a method for monitoring multinational theft of proprietary secrets.

A case for a biotechnology cartel can be made by examining the issues behind the often debated problem of technology transfer and the need for innovation. In the Western world, two strains of concern surround technology transfer: national defense issues and fears about the loss of technology as a resource. The national defense issue-the fear that the Soviet Union and other hostile powers will turn the finest new technology into the finest new weapons-is a cause for judicious control of information. Recent attempts, however, by the Reagan administration to disrupt presentation of certain scientific papers and to limit the importation of computer parts into neutral countries near Soviet borders moves far beyond national security concerns. It masks a far deeper concern-the possibility that other countries can exceed America's rate of industrial innovation and threaten the role of the U.S. in the international marketplace.

The solution to the problem of technical information flow will not be found by plugging technology leaks as they appear. As a recently released report by the National Academy of Sciences (NAS) concludes, there is a desperate need, as far as the U.S. is concerned, to develop a longterm strategy to accelerate industrial innovation. The encouragement of basic research and education in the sciences and engineering will be a far better solution to loss of technological supremacy than the blocking of international exchanges.

The NAS made a second useful recommendation which could apply to other countries as well as to the U.S.: unfair barriers to international commerce of new technologies and products should be resolved. A more lively exchange of new technologies and products, along with the increased risk that nations will rapidly learn new techniques through this commerce, requires full recognition of two simple concepts: technology, unlike specific products, is never lost when it is transported to other powers; and technology can be bartered for complementary technology, products, or marketing services once a system of exchange is agreed upon. As long as a corporation or a country can receive benefits which will accelerate its product development, there is no "loss of technology" in any technology transfer.

The bartering of technology can be applied across economic systems with different forms of administration as well as different levels of development. Particularly in the case of biotechnologies which have sweeping applications at the most basic industrial levels, socialist and capitalist countries with very divergent needs can justify these exchanges. One fundamental shift needs to occur before countries seriously address biotechnology barter on an international level: governments must view themselves as entrepreneurs for their countries as well as defenders of special interest groups which control their economies.

Both the developed and the developing nations of the world could benefit from a formal system of bartering biotechnology with a minimum of risk. If a set of international standards can be established, developed countries can enjoy the assurance that technology can be protected until exchanged with other countries for local marketing privileges, import privileges, access to researchers and complementary technologies, or the natural resources of biotechnology. Countries which literally steal these technologies or permit their corporations to engage in obvious industrial espionage could be penalized through loss of access to future agreements.

In any formal system of technology exchange, whether it is sponsored by the United Nations or any other agency, the risk exists that the third world countries will be compelled to cooperate on grossly unfair terms, repeating the misfortunes of earlier periods of industrial innovation. In considering biotechnology's transfer, two arguments can be made against this point: some of the new biological techniques, particularly in the areas of food and agriculture, can be tailored to fit developing economies more easily than the high capital and heavy machinery requirements which characterized earlier industrial revolutions; and now, unlike other periods, third world countries have more awareness and ability to control and actively barter their biotechnological resources, research talents and opportunities.

If the proposed UNIDO plan to establish a biotechnology research center to assist developing countries becomes a reality, this center could play an important role in strengthening the capacity of third world countries to exchange their expertise with nations which have made important strides in bio R\&D. A formal exchange system could shape such a center in positive ways, enabling affiliated researchers to concentrate on complementary, exchangeable technologies instead of duplicating the achievements of others.

A method and mechanism for bartering biotech research and products is subject to the severe limitations of any proposals for international cooperation. The power struggles, the squabbling for turf, the mutual accusations of unfair play, and the ultimate lack of an enforceable power would limit the success of such a system. Despite these limitations, such a system is worth exploring. If it serves to increase the level of biotechnological innovation in the international economy by increasing exchange of industrial information, all participating countries stand to benefit.
-Christopher Edwards 